\title{
Joint associations of folate, homocysteine and MTHFR, MTR and MTRR gene polymorphisms with dyslipidemia in a Chinese hypertensive population: a cross-sectional study
}

Wen-Xing $\mathrm{Li}^{1,2+}$, Wen-Wen $\mathrm{Lv}^{3+}$, Shao-Xing Dai ${ }^{2}$, Ming-Luo Pan ${ }^{3}$ and Jing-Fei Huang ${ }^{2,4,5^{*}}$

\begin{abstract}
Background: Dyslipidemia is a well-established risk factor for cardiovascular disease. Serum lipids were affected by several gene polymorphisms, folate, homocysteine and other metabolite levels. We aim to investigate the effects of homocysteine metabolism enzyme polymorphisms (MTHTR C677T, MTHFR A1298C, MTR A2756G and MTRR A66G) and their interactions with folate, homocysteine on serum lipid levels in Chinese patients with hypertension.

Methods: Participants were 480 hypertensive adults that enrolled in September to December 2005 from six different Chinese hospitals (Harbin, Shanghai, Shenyang, Beijing, Xi'an, and Nanjing). Known MTHFR C677T, MTHFR A1298C, MTR A2756G and MTRR A66G genotypes were determined by PCR-RFLP methods. Serum folate was measured by chemiluminescent immunoassay, homocysteine was measured by high-performance liquid chromatography, serum lipids parameters were determined by an automatic biochemistry analyzer, low-density lipoprotein was calculated by Friedewald's equation. Unitary linear regression model was used to assess the associations of gene polymorphisms, folate and homocysteine on serum lipid profiles. Unconditional logistic regression model was applied to test the interactions of folate, homocysteine and gene polymorphisms on dyslipidemia.
\end{abstract}

Results: No correlations between gene polymorphisms and homocysteine on serum lipid profiles. Compared with normal folate patients, patients with low folate showed higher odds of hypertriglyceridemia $(\mathrm{OR}=2.02,95 \% \mathrm{Cl}$ : 1.25-3.25, $\mathrm{P}=0.004)$ and low levels of high-density lipoprotein cholesterol $(\mathrm{OR}=1.88,95 \% \mathrm{Cl}: 1.07-3.28, \mathrm{P}=0.027)$. Each of four gene polymorphisms (MTHTR C677T, MTHFR A1298C, MTR A2756G and MTRR A66G) combined with low folate showed higher odds of hypertriglyceridemia (P for trend: 0.049, 0.004, 0.007 and 0.005, respectively). MTHFR C677T and A1298C with low folate showed higher odds of low levels of high-density lipoprotein cholesterol (P for trend: 0.008 and 0.031).

Conclusions: Low folate status and homocysteine metabolism gene polymorphisms (MTHTR C677T, MTHFR A1298C, MTR A2756G and MTRR A66G) may have a synergistic effect increased the incidence of dyslipidemia in Chinese hypertensive population.

Keywords: MTHFR C677T, MTHFR A1298C, MTR A2756G, MTRR A66G, Folate, Homocysteine, Serum lipids

\footnotetext{
* Correspondence: huangjf@mail.kiz.ac.cn

${ }^{\dagger}$ Equal contributors

${ }^{2}$ State Key Laboratory of Genetic Resources and Evolution, Kunming Institute of Zoology, Chinese Academy of Sciences, Kunming 650223, PR China ${ }^{4}$ KIZ-SU Joint Laboratory of Animal Models and Drug Development, College of Pharmaceutical Sciences, Soochow University, Suzhou 215123, PR China Full list of author information is available at the end of the article
} 


\section{Background}

Cardiovascular diseases (CVDs) are still a major cause of morbidity and mortality worldwide, which is expected to remain the same during the foreseeable future [1]. Dyslipidemia is a major risk factor for stroke, coronary artery disease, atherosclerosis and other CVDs [2-4]. Sun et al. showed that $64.4 \%$ of rural Chinese adults had at least one type of abnormal lipid concentration [5]. The prevalence of dyslipidemia in Chinese was higher than that in American [6], Canadian [7], and Iranian population [8]. In addition, abnormal folate or homocysteine (Hcy) level was also exacerbated the incidence of CVDs $[9,10]$. Recently, a large sample of clinical trials showed folate supplements effectively lower Hcy level and reduced the risk of stroke [11]. However, the potential mechanisms of folate, Hcy and serum lipid levels remain to be explored.

Our previous study found Hcy metabolism gene polymorphisms (MTHFR and MTRR) are significantly associated with serum lipid levels [12]. These findings suggest that there is an inherent correlation among folate, Hcy and lipid profiles. Additionally, several studies showed that medical nutrition therapy with folate intake significantly reduced serum lipids levels [13, 14]. Thus, we speculate that Hcy-metabolism gene polymorphisms associated with folate and Hcy interactively affect the incidence of dyslipidemia.

Several key enzymes, including methylenetetrahydrofolate reductase (MTHFR) [15], methionine synthase (MTR) [16] and methionine synthase reductase (MTRR) [17] are important in folate and Hcy metabolism and also in methylation reactions. MTHFR converts 5, 10methylenetetrahydrofolate into 5-methyltetrahydrofolate and this reaction provide a methyl for homocysteine into methionine in the catalyzed by MTR [18]. MTR requires vitamin $\mathrm{B}_{12}$ (cobalamin) as a coenzyme. Over time, the cobalamin(I) cofactor of MTR will be oxidized to cobalamin(II) which leads to inactivation of MTR. And MTRR restore oxidized cobalamin(II) to $\mathrm{CH}_{3}$-cobalamin(III) in order to maintain the activity of MTR [17]. MTHFR C677T (rs1801133) is a common mutation of MTHFR and its suggested being an unfavorable factor for cardiovascular diseases $[19,20]$. Yilmaz et al. showed that the $\mathrm{C}$ allele has a protective effect on blood lipid concentration and the T allele has a harmful effect when they are screening MTHFR C677T polymorphism in renal transplant patients [21]. However, another mutation MTHFR A1298C (rs1801131) seemed have no influences on serum lipids levels [12]. In hyperlipidemia patients, $M T R$ A2756G (rs1805087) mutation was associated with a higher level of total cholesterol and low-density lipoprotein cholesterol [22]. MTRR A66G (rs1801394) is a susceptible marker of congenital heart defects [23], but the effect of this mutation on lipid profiles still no conclusion.
We hypothesized that homocysteine metabolism gene polymorphisms in combination with a low folate level or a high Hcy level may affect serum lipid profiles. In this study, we aim to explore the independent associations of folate, Hcy and these four gene polymorphisms (MTHFR C677T, MTHFR A1298C, MTR A2756G and MTRR A66G) on serum lipid profiles, as well as to evaluate the joint effect of gene, Hcy and genotypes on dyslipidemia in Chinese hypertensive patients.

\section{Results}

\section{Clinical characteristics and genotype distributions}

A total of 480 patients were recruited for this study. Since 55 patients missing the data of genotypes or lipids parameters were excluded, a total of 425 subjects were included in our final analysis. The average age of our patients was $56.7 \pm 9.9$ years, including $185(43.5 \%)$ men and 240 (56.5 \%) women (Table 1). Genotype frequencies in the total population were showed in Table 2. Four gene polymorphisms (MTHFR C677T, MTHFR A1298C, MTR A2756G and MTRR A66G) in this population had no deviation from the Hardy-Weinberg equilibrium (P values were $0.885,0.384,0.937$ and 0.400 , respectively).

Table 1 Clinical and epidemiologic characteristics of population

\begin{tabular}{|c|c|}
\hline Characteristic & Value \\
\hline Age, year & $56.7 \pm 9.9$ \\
\hline \multicolumn{2}{|l|}{ Sex } \\
\hline Male & $185(43.5)$ \\
\hline Female & $240(56.5)$ \\
\hline Height, cm & $162.7 \pm 8.1$ \\
\hline Weight, kg & $68.2 \pm 11.0$ \\
\hline $\mathrm{BMI}, \mathrm{kg} / \mathrm{m}^{2}$ & $25.7 \pm 3.4$ \\
\hline $\mathrm{SBP}, \mathrm{mm} \mathrm{Hg}$ & $153.9 \pm 11.1$ \\
\hline $\mathrm{DBP}, \mathrm{mm} \mathrm{Hg}$ & $92.9 \pm 8.1$ \\
\hline Folate, $\mathrm{nmol} / \mathrm{L}$ & $13.7 \pm 5.8$ \\
\hline $\mathrm{Hcy}, \mu \mathrm{mol} / \mathrm{L}$ & $15.1 \pm 11.2$ \\
\hline $\mathrm{TC}, \mathrm{mmol} / \mathrm{L}$ & $5.00 \pm 1.11$ \\
\hline $\mathrm{TAG}, \mathrm{mmol} / \mathrm{L}$ & $1.74 \pm 1.24$ \\
\hline $\mathrm{HDL}-\mathrm{C}, \mathrm{mmol} / \mathrm{L}$ & $1.31 \pm 0.36$ \\
\hline $\mathrm{LDL}-\mathrm{C}, \mathrm{mmol} / \mathrm{L}$ & $2.92 \pm 0.79$ \\
\hline \multicolumn{2}{|l|}{ Clinical Centers } \\
\hline Ha'rbin & $52(12.2)$ \\
\hline Shanghai & $52(12.2)$ \\
\hline Shenyang & 78 (18.4) \\
\hline Beijing & $95(22.4)$ \\
\hline Xi'an & $71(16.7)$ \\
\hline Nanjing & 77 (18.1) \\
\hline
\end{tabular}

$B M I$ body mass index, SBP systolic blood pressure, DBP diastolic blood pressure, Hcy homocysteine, TC total cholesterol, TAG triacylglycerols, HDL-C high-density lipoprotein cholesterol, LDL-C low-density lipoprotein cholesterol 
Table 2 Hardy-Weinberg equilibrium test of four genotypes

\begin{tabular}{|c|c|c|c|c|}
\hline Genotype & Observed frequency & Expected frequency & $x^{2}$ & $P$ \\
\hline \multicolumn{5}{|c|}{ MTHFR C677T } \\
\hline $\mathrm{CC}$ & $108(25.4)$ & $107.3(25.2)$ & 0.021 & 0.885 \\
\hline CT & 211 (49.6) & $212.5(50.0)$ & & \\
\hline$\pi$ & $106(24.9)$ & $105.3(24.8)$ & & \\
\hline \multicolumn{5}{|c|}{ MTHFR A1298C } \\
\hline AA & $299(70.4)$ & $296.5(69.8)$ & 0.759 & 0.384 \\
\hline$A C$ & $112(26.4)$ & $116.9(27.5)$ & & \\
\hline $\mathrm{CC}$ & $14(3.3)$ & $11.5(2.7)$ & & \\
\hline \multicolumn{5}{|c|}{ MTR A2756G } \\
\hline AA & 348 (81.9) & $347.9(81.9)$ & 0.006 & 0.937 \\
\hline$A G$ & $73(17.2)$ & $73.3(17.2)$ & & \\
\hline GG & $4(0.9)$ & $3.9(0.9)$ & & \\
\hline \multicolumn{5}{|l|}{ MTRR A66G } \\
\hline AA & $137(32.2)$ & $141.2(33.2)$ & 0.708 & 0.400 \\
\hline$A G$ & $216(50.8)$ & $207.5(48.8)$ & & \\
\hline GG & $72(16.9)$ & $76.2(17.9)$ & & \\
\hline
\end{tabular}

\section{Associations of folate, Hcy and lipid profiles}

The associations of serum folate and lipid profiles were showed in Table 3. Although folate may have no influence on serum $\mathrm{TC}$ and LDL-C, there was a significant negative correlation between folate and TAG before adjusted covariates $(\beta(\mathrm{SE})$ : $-0.11(0.01), \mathrm{P}=0.029)$. However, when adjusted several confounding factors this correlation disappeared. Furthermore, we observed a positive correlation between folate and HDL-C (crude $\beta$ (SE): 0.15 (0.00), $\mathrm{P}=0.002$; adjusted $\beta$ (SE): 0.14 (0.00), $\mathrm{P}=0.002)$. We further used folate as a dichotomous variable to assess the influences of low folate on dyslipidemia (Table 4). Consistent with table three, patients with low folate showed higher odds of hypertriglyceridemia (OR (95 \% CI): 2.02 (1.25-3.25), P = 0.004) and low levels of high-density lipoprotein cholesterol (OR (95 \% CI): 1.88 (1.07-3.28), $\mathrm{P}=0.027)$.

We also analyzed the associations of Hcy and these lipid profiles. However, we had no significant findings

Table 3 Associations of folate level and serum lipid profiles

\begin{tabular}{|c|c|c|c|c|}
\hline \multirow[t]{2}{*}{ Parameters } & \multicolumn{2}{|l|}{ Crude } & \multicolumn{2}{|l|}{ Adjusted $^{\mathrm{b}}$} \\
\hline & $\beta(S E)^{a}$ & P & $\beta(S E)^{a}$ & P \\
\hline TC & $0.01(0.01)$ & 0.836 & $0.06(0.01)$ & 0.235 \\
\hline TAG & $-0.11(0.01)$ & 0.029 & $-0.07(0.01)$ & 0.151 \\
\hline HDL-C & $0.15(0.00)$ & 0.002 & $0.14(0.00)$ & 0.002 \\
\hline LDL-C & $-0.03(0.01)$ & 0.596 & $-0.00(0.01)$ & 0.984 \\
\hline
\end{tabular}

$\overline{T C}$ total cholesterol, TAG triacylglycerols, HDL-C high-density lipoprotein cholesterol, $L D L-C$ low-density lipoprotein cholesterol

${ }^{\mathrm{a}} \beta=$ regression coefficient

${ }^{\mathrm{b}}$ Adjusted for sex, age, clinical centers, height and weight (data not show). And high Hcy status had no effect on the incidence of dyslipidemia (data not show).

\section{Associations of genotypes and lipid profiles}

The correlations of these four gene polymorphisms and serum lipids levels were showed in Table 5. There was a marginal significance that the MTRR 66GG carriers had a higher serum total cholesterol level compared with 66AA carriers ( $\beta(\mathrm{SE})$ : 0.14 (0.09), $\mathrm{P}=0.054)$. We further analyzed the influences of gene polymorphisms on dyslipidemia risk, and the results were not reached significance (data not show).

Interactions of folate, Hcy and genotypes on dyslipidemia Compared with normal folate and wild-type carriers, those with low folate and mutant genotypes showed higher odds of hypertriglyceridemia (Table 6). In trend test, all these gene polymorphisms (MTHFR C677T, MTHFR A1298C, MTR A2756G and MTRR A66G) with low folate increased the prevalence of hypertriglyceridemia (interaction of MTHFR C677T and folate: $\mathrm{P}=0.049$; interaction of MTHFR A1298C and folate: $\mathrm{P}=0.004$; interaction of MTR A2756G and folate: $\mathrm{P}=0.007$; interaction of MTRR A66G and folate: $\mathrm{P}=0.005$, respectively). Table 7 showed the interactions of genotypes and low folate on low levels of high-density lipoprotein cholesterol. Compared with normal folate and MTHFR 677CC carriers, patients with both low folate and $677 \mathrm{CT}+\mathrm{TT}$ genotype showed higher odds of low levels of HDL-C (OR (95\% CI): 2.67 (1.08-6.60), $\mathrm{P}=0.033)$. Furthermore, low folate patients with the mutant allele of MTHFR A1298C showed a marginal significance higher incidence of low levels of HDL-C (OR (95 \% CI): 2.52 (0.97-6.57), $\mathrm{P}=0.059)$ than high folate patients carried 1298AA genotype. These findings were also confirmed by the trend test (interaction of MTHFR C677T and folate: $\mathrm{P}=0.008$; interaction of MTHFR A1298C and folate: $\mathrm{P}=0.031$, respectively). However, for interactions of genotypes and low folate on hypercholesterolemia and high levels of LDL-C, we have no significant findings.

We also carried out the analysis of interactions of high Hcy and genotypes with dyslipidemia profiles. Regrettably, no dyslipidemia odds were observed to be associated with high Hcy and mutant genotypes (data not show).

\section{Discussion}

In the present study, we investigated the association of folate, Hcy and several gene polymorphisms (MTHFR C677T, MTHFR A1298C, MTR A2756G and MTRR A66G) on serum lipid profiles and assessed the interactions of folate, Hcy and genotypes with dyslipidemia. The results showed patients with folate deficiency showed higher odds of hypertriglyceridemia and low levels of HDL-C. Furthermore, these mutant genotypes 
Table 4 Effect of low folate on serum lipids status

\begin{tabular}{|c|c|c|c|c|c|c|c|c|}
\hline \multirow[t]{2}{*}{ Folate status $^{a}$} & \multicolumn{2}{|l|}{$\mathrm{TC}$} & \multirow[t]{2}{*}{ OR $(95 \% \mathrm{Cl})$} & \multirow[t]{2}{*}{$P^{b}$} & \multicolumn{2}{|l|}{ TAG } & \multirow[t]{2}{*}{ OR $(95 \% \mathrm{Cl})$} & \multirow[t]{2}{*}{$P^{b}$} \\
\hline & $>5.18$ & $\leq 5.18$ & & & $>1.70$ & $\leq 1.70$ & & \\
\hline High FA, \% & 71.5 & 72.3 & Ref. & & 63.9 & 76.2 & Ref. & \\
\hline \multirow[t]{3}{*}{ Low FA, \% } & 28.5 & 27.7 & $0.87(0.54-1.40)$ & 0.569 & 36.1 & 23.8 & $2.02(1.25-3.25)$ & 0.004 \\
\hline & HDL-C & & OR $(95 \% \mathrm{Cl})$ & $p^{b}$ & LDL-C & & OR $(95 \%$ Cl) & $p^{b}$ \\
\hline & $<1.04$ & $\geq 1.04$ & & & $>3.37$ & $\leq 3.37$ & & \\
\hline High FA, \% & 61.7 & 74.9 & Ref. & & 71.3 & 72.3 & Ref. & \\
\hline Low FA, \% & 38.3 & 25.1 & $1.88(1.07-3.28)$ & 0.027 & 28.7 & 27.7 & $0.91(0.56-1.48)$ & 0.698 \\
\hline
\end{tabular}

TC total cholesterol, TAG triacylglycerols, HDL-C high-density lipoprotein cholesterol, LDL-C low-density lipoprotein cholesterol

${ }^{a}$ High FA: serum folate level $\geq 10 \mathrm{nmol} / \mathrm{L}$, Low FA: serum folate level $<10 \mathrm{nmol} / \mathrm{L}$

${ }^{\mathrm{b}}$ Adjusted for sex, age, clinical centers, height and weight

combined with low folate may synergistically affect the incidence of hypertriglyceridemia and low levels of HDL-C. However, we haven't found homocysteine directly or indirectly affected serum lipid profiles.

The mutation of MTHFR C677T is located in the catalytic domain of the enzyme, cause an alanine to valine substitution at position 222 of the enzyme, and result in a thermolabile enzyme [15, 24]. A previous study reported that homozygous mutation of 677TT reduced by approximately $70 \%$ of the mean enzyme activity and the heterozygous mutation of $677 \mathrm{CT}$ reduced by approximately $35 \%$ of the mean MTHFR activity [15]. It is no doubt that MTHFR C677T polymorphism was related to elevate plasma Hcy concentration and lower folate level [25-27]. Whereas its effect on lipid profiles is no conclusion. Frelut et al. showed MTHFR C677T significantly increased LDL-C level, and this mutant may also associate with higher total cholesterol and triacylglycerols levels, and lower HDL-C level, although it did not reach significance [28]. In polycystic ovary syndrome women, patients with $677 \mathrm{CT}$ genotype have higher serum total cholesterol and triacylglycerols than 677CC carriers [29]. In northern Chinese subjects with hyperlipidemia, individual carried MTHFR 677CT + TT genotypes showed higher triacylglycerols and total homocysteine compared with wild-type [22]. However, Chen et al. found no significant association between MTHFR C677T and lipid profiles (TC, TAG, HDL-C and LDL-C) in total population, but in subgroup analysis, the mutant $\mathrm{T}$ allele carriers have higher total cholesterol and low-density lipoprotein cholesterol than $677 \mathrm{CC}$ group in women [30]. In another Chinese clinical research, both plasma Hcy level and MTHFR C677T mutant have no association with hyperlipidemia or serum lipid levels [31]. In our study, MTHFR C677T may not affect serum lipid levels, and high homocysteine concentration also has no effect on serum lipid levels or dyslipidemia profiles. Furthermore, interaction of MTHFR C677T and Hcy also showed no influence on dyslipidemia. However, there was a trend for the combination of MTHFR $677 \mathrm{CT}+\mathrm{TT}$ and low folate significantly increased the incidence of hypertriglyceridemia and low levels of HDL-C. Mikael et al. found that MTHFR deficiency affects apolipoprotein levels and leads to lipid deposition, in mice with MTHFR deficiency showed higher plasma TAG level than controls [32]. Based on the negative correlation between MTHFR C677T and folate level [33], and the detrimental effect of folate deficiency on lipid metabolism [34], we speculate that MTHFR C677T polymorphism and folate deficiency interactively increased the prevalence of dyslipidemia.

The mutation of MTHFR A1298C resulted the substitution of adenine to cytosine at nucleotide 1298 position, cause a glutamic acid to alanine substitution at position 429 of the peptide, is located in the regulatory domain named NADPH and S-adenosyl methionine binding site $[24,35]$. Experimental results show that the A1298C mutation wasn't caused a thermolabile enzyme [35]. Publications about the influence of MTHFR A1298C mutant on blood lipid profiles were relatively small. In a previous study, both MTHFR C677T and MTHFR A1298C polymorphisms not affect total cholesterol level [36]. Additionally, Chang et al. found no association between MTHFR C677T and MTHFR A1298C on blood lipid profiles (TC, TAG, HDL and LDL) [37]. These results were consisted with our findings, MTHFR A1298C independent not associated with serum lipids level and also have no effect on dyslipidemia profiles. However, low folate patients carried MTHFR 1298 AC + CC showed a higher risk of hypertriglyceridemia and low levels of HDL-C compared with the high folate patients with 1298AA genotype, although the latter was marginal significance. An in vitro experiment showed folate has a direct protective effect on LDL oxidation and its doserelated [38]. However, an animal experiment showed folate deficiency did not influence triacylglycerol levels [32]. Therefore, the potential mechanisms of the joint effect between MTHFR A1298C and folate deficiency on dyslipidemia need further research.

In our study, MTR A2756G polymorphism independently not affects serum lipid profile or dyslipidemia. However, the 
Table 5 Associations of genotypes and serum lipid profiles

\begin{tabular}{|c|c|c|c|c|c|c|}
\hline \multirow[t]{2}{*}{ Genotype } & \multicolumn{3}{|l|}{$\mathrm{TC}$} & \multicolumn{3}{|l|}{ TAG } \\
\hline & $\overline{M e a n} \pm$ SD & $\beta(S E)^{a}$ & $\mathrm{P}^{\mathrm{b}}$ & Mean \pm SD & $\beta(S E)^{a}$ & $P^{b}$ \\
\hline \multicolumn{7}{|c|}{ MTHFR C677Т } \\
\hline $\mathrm{CC}$ & $5.01 \pm 1.42$ & Reference & & $1.75 \pm 1.06$ & Reference & \\
\hline CT & $4.94 \pm 0.98$ & $-0.05(0.13)$ & 0.337 & $1.75 \pm 1.19$ & $-0.01(0.13)$ & 0.799 \\
\hline$\pi$ & $5.12 \pm 1.00$ & $0.02(0.08)$ & 0.811 & $1.69 \pm 1.49$ & $-0.03(0.08)$ & 0.701 \\
\hline \multicolumn{7}{|c|}{ MTHFR A1298C } \\
\hline $\mathrm{AA}$ & $4.97 \pm 0.98$ & Reference & & $1.69 \pm 1.15$ & Reference & \\
\hline$A C$ & $5.10 \pm 1.45$ & $0.05(0.12)$ & 0.263 & $1.89 \pm 1.48$ & $0.06(0.13)$ & 0.231 \\
\hline $\mathrm{CC}$ & $4.94 \pm 0.83$ & $0.01(0.12)$ & 0.846 & $1.56 \pm 0.94$ & $-0.03(0.15)$ & 0.633 \\
\hline \multicolumn{7}{|c|}{ MTR A2756G } \\
\hline AA & $5.02 \pm 1.11$ & Reference & & $1.76 \pm 1.30$ & Reference & \\
\hline$A G$ & $4.92 \pm 1.09$ & $-0.00(0.14)$ & 0.966 & $1.62 \pm 0.93$ & $-0.02(0.15)$ & 0.698 \\
\hline GG & $5.18 \pm 2.23$ & $0.02(0.28)$ & 0.714 & $1.73 \pm 0.40$ & $-0.02(0.31)$ & 0.703 \\
\hline \multicolumn{7}{|c|}{ MTRR A66G } \\
\hline $\mathrm{AA}$ & $4.82 \pm 0.99$ & Reference & & $1.71 \pm 1.25$ & Reference & \\
\hline$A G$ & $5.03 \pm 0.95$ & $0.09(0.10)$ & 0.091 & $1.77 \pm 1.30$ & $-0.01(0.13)$ & 0.853 \\
\hline GG & $5.27 \pm 1.64$ & $0.14(0.09)$ & 0.054 & $1.70 \pm 1.03$ & $-0.02(0.08)$ & 0.757 \\
\hline \multirow[t]{2}{*}{ Genotype } & $\mathrm{HDL}-\mathrm{C}$ & & & LDL-C & & \\
\hline & Mean \pm SD & $\beta(\mathrm{SE})^{\mathrm{a}}$ & $P^{b}$ & Mean \pm SD & $\beta(\mathrm{SE})^{\mathrm{a}}$ & $P^{b}$ \\
\hline \multicolumn{7}{|c|}{ MTHFR C677Т } \\
\hline $\mathrm{CC}$ & $1.33 \pm 0.36$ & Reference & & $2.87 \pm 0.83$ & Reference & \\
\hline CT & $1.28 \pm 0.35$ & $-0.08(0.04)$ & 0.111 & $2.91 \pm 0.80$ & $0.01(0.10)$ & 0.801 \\
\hline$\pi$ & $1.34 \pm 0.39$ & $-0.01(0.02)$ & 0.904 & $2.97 \pm 0.74$ & $0.04(0.05)$ & 0.550 \\
\hline \multicolumn{7}{|c|}{ MTHFR A1298C } \\
\hline $\mathrm{AA}$ & $1.30 \pm 0.36$ & Reference & & $2.93 \pm 0.77$ & Reference & \\
\hline$A C$ & $1.31 \pm 0.36$ & $0.02(0.04)$ & 0.689 & $2.89 \pm 0.84$ & $-0.02(0.09)$ & 0.707 \\
\hline $\mathrm{CC}$ & $1.39 \pm 0.48$ & $0.08(0.05)$ & 0.129 & $2.92 \pm 0.82$ & $0.00(0.11)$ & 0.993 \\
\hline \multicolumn{7}{|c|}{ MTR A2756G } \\
\hline $\mathrm{AA}$ & $1.31 \pm 0.37$ & Reference & & $2.91 \pm 0.78$ & Reference & \\
\hline$A G$ & $1.28 \pm 0.33$ & $-0.02(0.04)$ & 0.658 & $2.91 \pm 0.84$ & $0.01(0.10)$ & 0.784 \\
\hline GG & $1.33 \pm 0.42$ & $0.04(0.09)$ & 0.456 & $3.39 \pm 0.85$ & $0.06(0.20)$ & 0.288 \\
\hline \multicolumn{7}{|l|}{ MTRR A66G } \\
\hline AA & $1.27 \pm 0.37$ & Reference & & $2.85 \pm 0.79$ & Reference & \\
\hline$A G$ & $1.32 \pm 0.35$ & $0.06(0.04)$ & 0.223 & $2.94 \pm 0.80$ & $0.06(0.09)$ & 0.303 \\
\hline GG & $1.36 \pm 0.37$ & $0.07(0.03)$ & 0.274 & $2.98 \pm 0.77$ & $0.06(0.06)$ & 0.369 \\
\hline
\end{tabular}

TC total cholesterol, TAG triacylglycerols, HDL-C high-density lipoprotein cholesterol, $L D L-C$ low-density lipoprotein cholesterol

${ }^{\mathrm{a}} \beta=$ regression coefficient

${ }^{\mathrm{b}}$ Adjusted for sex, age, clinical centers, height and weight

mutant allele with low folate may elevate the incidence of hypertriglyceridemia. The A2756G mutation in MTR that located at position 919 of the protein, results in substitution of glycine for aspartic acid [39]. It's located in a domain of the protein that interacts with $\mathrm{S}$-adenosyl methionine (SAM) and auxiliary proteins that are required for the reductive methylation and reactivation of the vitamin $\mathrm{B}_{12}$ Cofactor, which can be inactivated by oxidation during catalysis $[17,40]$. Therefore, it is possible that the mutant might impair the binding of SAM and/or auxiliary proteins [40] and increased plasma homocysteine concentration [41]. In hyperlipidemia patients, MTR 2756AG + GG carriers have higher total cholesterol and low-density lipoprotein cholesterol than those 2756AA carriers [22]. Additionally, the prevalence of $2756 \mathrm{AG}+\mathrm{GG}$ genotypes in the combined hyperlipidemia group (hypercholesterolemia 
Table 6 Interactions of genotypes and low folate with hypertriglyceridemia

\begin{tabular}{|c|c|c|c|c|c|c|c|}
\hline Genotype & Folate status $^{a}$ & High TAG ${ }^{\mathrm{b}}$ & Low TAG ${ }^{b}$ & OR $(95 \%$ Cl) & $p^{c}$ & Trend test & $p^{c}$ \\
\hline \multicolumn{8}{|c|}{ MTHFR C677T } \\
\hline CC & High FA & $30(20.8)$ & $54(19.2)$ & Reference & & \multirow[t]{4}{*}{$0.10(0.02)$} & \multirow[t]{4}{*}{0.049} \\
\hline$C T+\pi$ & High FA & $62(43.1)$ & $160(56.9)$ & $0.66(0.38-1.16)$ & 0.153 & & \\
\hline $\mathrm{CC}$ & Low FA & $11(7.6)$ & $13(4.6)$ & $1.44(0.43-4.81)$ & 0.555 & & \\
\hline$C T+T$ & Low FA & $41(28.5)$ & $54(19.2)$ & $1.44(0.70-2.94)$ & 0.325 & & \\
\hline \multicolumn{8}{|c|}{ MTHFR A1298C } \\
\hline AA & High FA & $60(41.7)$ & $151(53.7)$ & Reference & & \multirow[t]{4}{*}{$0.14(0.02)$} & \multirow[t]{4}{*}{0.004} \\
\hline$A C+C C$ & High FA & $32(22.2)$ & $63(22.4)$ & $1.27(0.74-2.17)$ & 0.388 & & \\
\hline $\mathrm{AA}$ & Low FA & $38(26.4)$ & $50(17.8)$ & $2.23(1.27-3.91)$ & 0.005 & & \\
\hline$A C+C C$ & Low FA & $14(9.7)$ & $17(6.0)$ & $2.51(1.07-5.89)$ & 0.035 & & \\
\hline \multicolumn{8}{|c|}{ MTR A2756G } \\
\hline AA & High FA & 76 (52.8) & $180(64.1)$ & Reference & & \multirow[t]{4}{*}{$0.13(0.02)$} & \multirow[t]{4}{*}{0.007} \\
\hline$A G+G G$ & High FA & $16(11.1)$ & $34(12.1)$ & $1.09(0.55-2.16)$ & 0.802 & & \\
\hline AA & Low FA & $41(28.5)$ & $51(18.1)$ & $2.05(1.20-3.52)$ & 0.009 & & \\
\hline$A G+G G$ & Low FA & $11(7.6)$ & $16(5.7)$ & $1.92(0.82-4.53)$ & 0.134 & & \\
\hline \multicolumn{8}{|l|}{ MTRR A66G } \\
\hline AA & High FA & $24(16.7)$ & 78 (27.8) & Reference & & \multirow[t]{4}{*}{$0.14(0.02)$} & \multirow[t]{4}{*}{0.005} \\
\hline$A G+G G$ & High FA & $68(47.2)$ & $136(48.4)$ & $1.47(0.84-2.57)$ & 0.173 & & \\
\hline AA & Low FA & 17 (11.8) & $18(6.4)$ & $3.39(1.31-8.79)$ & 0.012 & & \\
\hline$A G+G G$ & Low FA & $35(24.3)$ & 49 (17.4) & $2.51(1.21-5.19)$ & 0.013 & & \\
\hline
\end{tabular}

TAG triacylglycerols

aHigh FA: serum folate level $\geq 10 \mathrm{nmol} / \mathrm{L}$, Low FA: serum folate level $<10 \mathrm{nmol} / \mathrm{L}$

${ }^{b}$ High TAG: serum TAG > $1.70 \mathrm{mmol} / \mathrm{L}$; Low TAG: serum TAG $\leq 1.70 \mathrm{mmol} / \mathrm{L}$

${ }^{\mathrm{C}}$ Adjusted for sex, age, clinical centers, height and weight

and hypertriglyceridemia) was significantly higher than that in the control group [22]. Regardless of some research found no association between MTR A2756G and folate level [25, 27], a study showed serum folate level, MTHFR $677 C C+C T$ and MTR 2756AA genotypes have a significant interaction on total homocysteine concentration in pregnant woman [25]. Furthermore, individuals with low intake of folate, vitamin $\mathrm{B}_{6}$ and vitamin $\mathrm{B}_{12}$, the MTHFR $677 \mathrm{~T}$ allele and MTR 2756G allele were associated with a higher risk of breast cancer [42]. These results indicate that the mutation of MTR A2756G with other unfavorable factors may affect serum lipid profiles.

Our study showed a borderline significant that MTRR 66GG elevated serum TC level. Difference with our results, a previous study suggested that individual with MTRR 66GG genotype have lower serum TC and LDL-C level than 66AA carriers in Chinese hypertensive patients [12]. The mutation of MTRR A66G is the substitution of A for $\mathrm{G}$ at nucleotide 66 with a substitution of an isoleucine by a methionine. It has been suggested that the mutation is located in the putative flavin mononucleotide-binding domain of the MTRR enzyme that interacts with MTR [17] and thus disrupt the binding of MTRR to the MTR-cobalamin-complex, thereby decreasing the rate of homocysteine remethylation [39]. Our results showed MTRR 66AA patients with low folate had a 3.4-fold risk of hypertriglyceridemia and a 4.7-fold of high levels of LDL-C. Numerous studies showed MTRR A66G was a risk factor for congenital heart defects [23, 43, 44]. But the effect of this mutation on blood lipid profiles was lack of research. So we believe that the joint associations of MTRR A66G and folate with dyslipidemia are worthy to be further study.

Folate plays an important role in one-carbon metabolism. It serves as a catalytic substrate for the transfer of one-carbon units. When fed folate deficiency or methyl donor deficiency diets, rats showed lower hepatic folate, phosphocholine (PC) storage and higher plasma homocysteine, glycine, serine and threonine concentrations [45]. Furthermore, compared with control animals, rats with folate or methyl donor deficiency showed several protein regulation disorder and abnormal gene expression in liver [45]. Additionally, folate deficiency will elevate liver triacylglycerols level in spontaneously hypertensive rats [46]. These studies indicate that folate deficiency will damage the hepatic lipid homeostasis. Although short-term folate deficiency has weak impact on lipid metabolism, a long-term folate deficiency showed a 
Table 7 Interactions of genotypes and low folate with low levels of high-density lipoprotein cholesterol (HDL-C)

\begin{tabular}{|c|c|c|c|c|c|c|c|}
\hline Genotype & Folate status $^{a}$ & Low HDL-C ${ }^{b}$ & High HDL-C ${ }^{b}$ & OR $(95 \%$ Cl) & $P^{c}$ & Trend test & $P^{c}$ \\
\hline \multicolumn{8}{|c|}{ MTHFR C677T } \\
\hline $\mathrm{CC}$ & High FA & $13(13.8)$ & $71(21.5)$ & Reference & & $0.12(0.02)$ & 0.008 \\
\hline$C T+T$ & High FA & $45(47.9)$ & $177(53.5)$ & $1.82(0.87-3.81)$ & 0.114 & & \\
\hline $\mathrm{CC}$ & Low FA & $7(7.4)$ & $17(5.1)$ & $1.13(0.23-5.65)$ & 0.883 & & \\
\hline$C T+T$ & Low FA & 29 (30.9) & 66 (19.9) & $2.67(1.08-6.60)$ & 0.033 & & \\
\hline \multicolumn{8}{|c|}{ MTHFR A1298C } \\
\hline AA & High FA & $40(42.6)$ & $171(51.7)$ & Reference & & $0.10(0.02)$ & 0.031 \\
\hline$A C+C C$ & High FA & $18(19.1)$ & 77 (23.3) & $0.94(0.48-1.82)$ & 0.842 & & \\
\hline AA & Low FA & $24(25.5)$ & $64(19.3)$ & $1.59(0.82-3.08)$ & 0.172 & & \\
\hline$A C+C C$ & Low FA & $12(12.8)$ & $19(5.7)$ & $2.52(0.97-6.57)$ & 0.059 & & \\
\hline \multicolumn{8}{|c|}{ MTR A2756G } \\
\hline $\mathrm{AA}$ & High FA & $51(54.3)$ & 205 (61.9) & Reference & & $0.08(0.02)$ & 0.099 \\
\hline$A G+G G$ & High FA & $7(7.4)$ & $43(13.0)$ & $0.53(0.21-1.32)$ & 0.173 & & \\
\hline AA & Low FA & $27(28.7)$ & 65 (19.6) & $1.66(0.88-3.13)$ & 0.116 & & \\
\hline$A G+G G$ & Low FA & $9(9.6)$ & $18(5.4)$ & $1.73(0.66-4.52)$ & 0.263 & & \\
\hline \multicolumn{8}{|l|}{ MTRR A66G } \\
\hline $\mathrm{AA}$ & High FA & $17(18.1)$ & 85 (25.7) & Reference & & $0.07(0.02)$ & 0.142 \\
\hline$A G+G G$ & High FA & 41 (43.6) & $163(49.2)$ & $1.28(0.66-2.49)$ & 0.468 & & \\
\hline AA & Low FA & $19(20.2)$ & $16(4.8)$ & $4.66(1.67-13.06)$ & 0.003 & & \\
\hline$A G+G G$ & Low FA & $17(18.1)$ & $67(20.2)$ & $1.52(0.59-3.92)$ & 0.382 & & \\
\hline
\end{tabular}

${ }^{a}$ High FA: serum folate level $\geq 10 \mathrm{nmol} / \mathrm{L}$, Low FA: serum folate level $<10 \mathrm{nmol} / \mathrm{L}$

bLow HDL-C: serum HDL-C $<1.04 \mathrm{mmol} / \mathrm{L}$; High HDL-C: serum HDL-C $\geq 1.04 \mathrm{mmol} / \mathrm{L}$

'Adjusted for sex, age, clinical centers, height and weight

marked hepatic lipid accumulation in rats [45, 47]. In our study, folate was associated with higher serum TAG and lower serum HDL-C level, patients with low folate showed higher odds of hypertriglyceridemia and low levels of HDL-C. Similar to our findings, Kim et al. found serum folate levels were significantly and positively correlated with HDL cholesterol and negatively with TAG, although the latter showed borderline significance [48]. In homocysteine metabolism, folate as a methyl donor that provides methyl for the synthesis of $\mathrm{S}$-adenosyl methionine (SAM), SAM is a key intermediate in PC synthesis [49]. Decreased SAM level will increase S-adenosyl homocysteine (SAH), a competitive inhibitor of many methyltransferase reactions. So an important function of folate is maintenance the cellular SAM and SAH concentrations [34]. Therefore, folate deficiency will reduce PC synthesis resulting in accumulation of hepatic TAG that synthesis from phosphatidylethanolamine $\mathrm{N}$-methyltransferase (PEMT) derived PC [34]. Furthermore, folate deficiency also reduced PEMT activity and choline kinase expression, and induced the expression of genes involved in hepatic lipid synthesis [34]. In oral contraceptive-treated rats, those with low dietary folate showed lower plasma HDL level and higher LDL level than control groups [50]. Another study showed higher serum folate level was associated with a lower level of LDL-C, higher levels of HDL-C and a lower LDL-C-C/HDL-C-ratio [51]. Elevated level of LDL is related to pathogenesis of atherosclerotic vascular disease whereas HDL has antioxidant effect that beneficial for against atherosclerosis and antiinflammatory [3]. High Hcy was also suggested inducing hepatic cholesterol biosynthesis and lipid accumulation [52]. The liver is the main sites for lipids and Hcy metabolism. Hypomethylation associated with hyperhomocysteinemia was related to lipid accumulation in tissues, elevated Hcy increased SAH level thus inhibited PEMT and lower the production of PC from phosphatidylethanolamine [49]. An animal experiment showed a significant positive correlation between plasma Hcy and triacylglycerols in female mice [32].

Additionally, studies showed that serum lipid profiles were also regulated by vitamin $B_{6}$ and vitamin $B_{12}$. Fat oxidation requires carnitine and the endogenous synthesis of carnitine mainly occurs in the liver and kidneys and requires lysine, methionine and vitamin $B_{6}$ [53]. Furthermore, vitamin $B_{6}$ plays an important role in the desaturation and elongation of fatty acids, the mobilization of unsaturated fatty acids from triglycerides to phospholipids, and methylation of phospholipids [54]. Low vitamin 
$B_{6}$ level was reported to impair carnitine synthesis and hence alter the lipid profiles. However, vitamin $\mathrm{B}_{6}$ supplementation was found to reduce the different components of the lipid profile by $\sim 10 \%$, and significantly lowering TC and HDL-C level [53]. Vitamin $B_{12}$ is a crucial constituent of the one carbon cycle and plays an important role in the homocysteine metabolism. It's also a cofactor for the mitochondrial enzyme methyl malonyl CoA mutase and regulates the rate of long chain fatty acyl-CoA transfer into the mitochondria. Vitamin $B_{12}$ deficiency leads to the accumulation of fatty acids in the cytosol thereby influencing lipid metabolic pathways [55]. Adaikalakoteswari et al. reported that vitamin $B_{12}$ deficiency increased serum triglycerides and HDL level in Europeans and Indians with type 2 diabetes [56]. An animal experiment also showed the adverse effect of vitamin $\mathrm{B}_{12}$ deficiency on plasma lipid profiles and liver fatty acid levels [57]. However, Wasilewska et al. found no association between $\mathrm{B}$ vitamins (folate, vitamin $\mathrm{B}_{6}$ or vitamin $\mathrm{B}_{12}$ ) and lipid profiles in any examined group [58].

Therefore, we speculate that B vitamins, some metabolites and genotypes may synergistically affect the hepatic lipid metabolism and serum lipid profiles. However, the molecular mechanism of these metabolites under conditions of different gene polymorphisms on lipid profiles is not fully understood, and need for more extensive research.

\section{Conclusion and limitations}

Our study demonstrated that there was a joint effect of homocysteine-metabolism gene polymorphisms (MTHFR C677T, MTHFR A1298C, MTR A2756G and MTRR A66G) and low folate on dyslipidemia in Chinese hypertensive patients. However, the underlying mechanism is not clear. Therefore, we believe that future researches could be more effective to elucidate these findings in a wider population.

Our study had several limitations. Firstly, this was a cross-sectional study that we can't make a prediction about the incidence of dyslipidemia in the future, and the prevalence-incidence bias may also exist. Furthermore, our study sample was relatively small, and it may lack of effect when performed subgroup analysis. Next, serum lipid profiles may modify by vitamin $B_{6}$ and vitamin $B_{12}$, and we didn't determine these $B$ vitamins. Additionally, the limitation of generalization in our study was the study population only contained hypertensive adults, so these results need to be verified in a healthy population. In addition, serum lipid profiles may relate to dietary habits that we have not included.

\section{Methods}

\section{Participants and procedures}

This study was conducted using data collected in a previous study [59]. This was a multicenter, randomized, double-blind controlled trial in hypertensive Chinese adults. Details regarding "Study subjects", "Randomization and double blinding", "Data collection procedures", and "Laboratory tests" have been previously described [59]. Totally, 480 patients with mild or moderate hypertension were recruited from six hospitals in different Chinese regions (Ha'erbin, Shanghai, Shenyang, Beijing, Xi'an, and Nanjing) from September to December 2005. All six hospitals were certified as clinical pharmacology centers by the State Food and Drug Administration in China. This study was approved by the Ethics Committee of Peking University First Hospital, Beijing, China. The purpose and procedures of the study were carefully explained to all participants, and written informed consent was obtained from each participant.

\section{Anthropometric measurements}

The participants were invited to our clinic center at $8 \mathrm{am}$ the next day after fasting overnight. After $60 \mathrm{~min}$ resting in a supine position, supine blood pressures were measured by using a mercury sphygmomanometer. No alcohol, cigarette smoking, coffee or tea was taken before the measurements. Blood pressure was measured by trained nurses. According to World Health Organization (WHO) standardized criteria, SBP was recorded at the appearance of sounds (first Korotkoff sounds) and DBP was recorded at the disappearance of sounds (fifth Korotkoff sounds). Three consecutive measurements were taken on the arms with 30s interval between replicates. If the difference between the measurements was more than $4 \mathrm{~mm} \mathrm{Hg}$, the patient was asked to rest for $5 \mathrm{~min}$, and then repeated the measurements. In all of our analysis, the average of three consecutive blood pressure readings was used. Height was measured without shoes to the nearest $0.1 \mathrm{~cm}$ on a portable stadiometer. Weight was measured in light indoor clothing without shoes to the nearest $0.1 \mathrm{~kg}$. Body mass index (BMI) was calculated as weight (kilograms)/ height (meters) squared.

\section{Blood sample collection and laboratory methods}

After 10-12 h of fasting, a venous blood sample was obtained from each participant. Serum or plasma samples were separated within $15 \mathrm{~min}$ of collection, and were analyzed within $30 \mathrm{~min}$ or stored at $-80{ }^{\circ} \mathrm{C}$ for later analysis. Blood samples collected at baseline were used for the measurement of homocysteine (Hcy), folate and lipids levels. Serum lipids including total cholesterol (TC), triacylglycerols (TAG) and high density lipoprotein cholesterol (HDL-C) were performed in the six study center laboratories, using standard reagents and an automatic biochemistry analyzer. Low density lipoprotein cholesterol (LDL-C) was calculated by Friedewald's equation. Plasma Hcy concentration was determined in duplicate by high- 
performance liquid chromatography. The intra- and inter-assay coefficients of variation were $3.5 \%$ and $4.2 \%$, respectively. Serum folate was determined by chemiluminescent immunoassay using a Beckman Coulter ACCESS Immunoassay System (BeckmanCoulter Canada Inc., Mississauga, Canada). The intraand inter-assay coefficients of variation were $2.3 \%$ and $3.7 \%$, respectively. All sample collection and tests were performed in an identical manner following the same standard protocol.

\section{DNA extraction and genotyping}

All participants were requested to provide $2 \mathrm{ml}$ peripheral whole blood, which was collected in ethylenediaminetetraacetic acid (EDTA) and stored at $-20{ }^{\circ} \mathrm{C}$. Genomic DNA was extracted from the cell pellet in whole blood by the QIAamp Blood Kit (Qiagen, Valencia, California, USA) and evaluate for quality by $1 \%$ agarose gel electrophoresis. TaqMan probe technique was used for detecting gene polymorphisms of the Hcy pathway in the central laboratory. The polymerase chain reaction-restriction fragment length polymorphism (PCR-RFLP) method was applied to detect the MTHFR C677T, MTHFR A1298C, MTR A2756G and MTRR A66G genotypes. Universal reaction conditions for each genotyping are as follows: $4 \mathrm{ng}$ dried DNA, $0.08 \mathrm{~mL} 40$ assay locus-specific probe, and $2.0 \mathrm{~mL}$ TaqMan universal polymerase chain reaction (PCR) master mix made to a final volume of $4 \mathrm{~mL}$ with $1.92 \mathrm{~mL}$ of sterile water. Plus the main parameters for the PCR-RFLP of the four single nucleotide polymorphisms (SNPs) are shown in Table 8 . The amplified PCR products were separated on $3 \%$ agarose gel. To ensure the accuracy of the genotype, each sample had twice genotyping for the SNP in our present study by two independent researchers. Genotyping call rate for assessments of all genetic variants was $\geq 98 \%$ in this study. After excluding samples that consistently failed, we selected $10 \%$ of total samples for replication, and concordance of $100 \%$ was repeated for all samples.

\section{Thresholds of dyslipidemia, low folate and high Hcy}

According to Chinese Guidelines on Prevention and Treatment of Dyslipidemia in Adults [60], we defined the four types of dyslipidemia as: hypercholesterolemia (serum total cholesterol level $>5.18 \mathrm{mmol} / \mathrm{L}$ ); hypertriglyceridemia (serum triacylglycerols level $>1.70 \mathrm{mmol} / \mathrm{L}$ ); Low levels of high-density lipoprotein cholesterol (serum HDL-C level < $1.04 \mathrm{mmol} / \mathrm{L}$ ); high levels of lowdensity lipoprotein cholesterol (serum LDL-C level > $3.37 \mathrm{mmol} / \mathrm{L}$ ). In addition, low folate was considered to be serum folate level lower than $10 \mathrm{nmol} / \mathrm{L}$ [61], and high Hcy was defined as homocysteine concentration higher than $15 \mu \mathrm{mol} / \mathrm{L}[62,63]$.

\section{Statistical analysis}

Statistical analyses were using the IBM SPSS software package (version 19.0 for windows; IBM Inc. Armonk, NY, USA). The results for categorical variables (i.e. sex, clinical centers and genotypes) are presented as number and percentage of cases. Continuous variables (i.e. age, height, weight, body mass index (BMI), systolic blood pressure (SBP), diastolic blood pressure (DBP), folate, Hcy, TC, TAG, HDL-C and LDL-C) were given as the mean \pm standard deviation. The means for continuous variables in the two groups were compared using Student's $\mathrm{t}$ tests, and the prevalence of categorical variables was compared using $\chi^{2}$ tests. Hardy-Weinberg equilibrium for genotypic frequencies of four genes was assessed with the $X^{2}$ test and Fisher's exact test. Unitary linear regression model was used to access the associations of folate, Hcy and gene polymorphisms on serum lipids levels. Unconditional logistic regression was performed to estimate the independently effects of folate, Hcy status and genotypes on dyslipidemia risk. The interactions of folate, Hcy and genotypes on the incidence of dyslipidemia were also adopted the unconditional logistic regression model and used trend test for further verification. Since the number of cases was small, we adopted the stepwise logistic regression method (Backward: Wald). All analysis were adjusted potential confounding factors, including sex, age, clinical

Table 8 Primer sequences and reaction conditions for PCR-RFLP of gene polymorphisms

\begin{tabular}{|c|c|c|c|c|}
\hline Gene & Primer sequence & $\mathrm{T}^{\mathrm{a}}$ and Cycles & Product size & Restriction enzyme \\
\hline \multirow[t]{2}{*}{ MTHFR C677T } & Forward: 5'-TGAAGGAGAAGGTGTCTGCGGGA-3' & $58^{\circ} \mathrm{C}, 35$ & $198 \mathrm{bp}$ & Hinf I \\
\hline & Reverse: 5'-AGGACGGTGCGGTGAGAGTG-3' & & & \\
\hline \multirow[t]{2}{*}{ MTHFR A1298C } & Forward: 5'-CTTTGGGGAGCTGAAGGACTACTAC-3' & $52^{\circ} \mathrm{C}, 38$ & $163 \mathrm{bp}$ & Mbo II \\
\hline & Reverse: 5'-CACTTTGTGACCATTCCGGTTTG-3' & & & \\
\hline \multirow[t]{2}{*}{ MTR A2756G } & Forward: 5'-GAACTAGAAGACAGAAATTCTCTA-3' & $53^{\circ} \mathrm{C}, 36$ & $189 \mathrm{bp}$ & Hae III \\
\hline & Reverse: 5'-CATGGAAGAATATCAAGATATTAGA-3' & & & \\
\hline \multirow[t]{2}{*}{ MTRR A66G } & Forward: 5'-GCAAAGGCCATCGCAGAAGACAT-3' & $60^{\circ} \mathrm{C}, 35$ & $151 \mathrm{bp}$ & Nsp I \\
\hline & Reverse: 5'-GTGAAGATCTGCAGAAAATCCATGTA-3' & & & \\
\hline
\end{tabular}

${ }^{a}$ Annealing temperature 


\section{centers, height and weight. A two-sided P value $<0.05$ was considered as significant.}

\begin{abstract}
Abbreviations
MTHFR: Methylenetetrahydrofolate reductase; MTR: Methionine synthase; MTRR: Methionine synthase reductase; Hcy: Homocysteine; TC: Total cholesterol; TAG: Triacylglycerols; HDL-C: High-density lipoprotein cholesterol; LDL-C: Low-density lipoprotein cholesterol; BMl: Body mass index; SBP: Systolic blood pressure; DBP: Diastolic blood pressure.

\section{Competing interests}

The authors declare that they have no competing interests.

\section{Authors' contributions}

WXL and WWL carried out data analysis and drafted the manuscript. SXD and MLP edited the manuscript. JFH is the corresponding author. He also edited the manuscript. All authors read and approved the final manuscript.
\end{abstract}

\section{Acknowledgments}

This work was supported by the National Basic Research Program of China (Grant No. 2013CB835100), and the National Natural Science Foundation of China (Grant No. 31123005 to J.F.H and No. 31401142 to S.X.D). We gratefully thank Shanqun Jiang, Ph.D. (School of Life Sciences, Anhui University, Hefei, China; and Institute of Biomedicine, Anhui Medical University, Hefei, China) and Xiping Xu, M.D., Ph.D. (Institute of Biomedicine, Anhui Medical University, Hefei, China) for providing clinical trial data and helpful advice on the data analysis.

\section{Author details}

${ }^{1}$ Institute of Health Sciences, Anhui University, Hefei 230601, PR China. ${ }^{2}$ State Key Laboratory of Genetic Resources and Evolution, Kunming Institute of Zoology, Chinese Academy of Sciences, Kunming 650223, PR China. ${ }^{3}$ School of Life Sciences, Anhui University, Hefei 230601, PR China. ${ }^{4}$ KIZ-SU Joint Laboratory of Animal Models and Drug Development, College of Pharmaceutical Sciences, Soochow University, Suzhou 215123, PR China. ${ }^{5}$ Collaborative Innovation Center for Natural Products and Biological Drugs of Yunnan, Kunming 650223, PR China.

\section{Received: 25 June 2015 Accepted: 19 August 2015} Published online: 04 September 2015

\section{References}

1. Mozaffarian D, Benjamin EJ, Go AS, Arnett DK, Blaha MJ, Cushman M, et al. Heart disease and stroke statistics-2015 update: a report from the American Heart Association. Circulation. 2015:131:e29-322.

2. Pisciotta L, Bertolini S, Pende A. Lipoproteins, stroke and statins. Curr Vasc Pharmacol 2015:13:202-208.

3. Shao B, Heinecke JW. HDL, lipid peroxidation, and atherosclerosis. J Lipid Res. 2009:50:599-601.

4. Emerging Risk Factors C, Di Angelantonio E, Gao P, Pennells L, Kaptoge S, Caslake $M$, et al. Lipid-related markers and cardiovascular disease prediction. JAMA. 2012:307:2499-506.

5. Sun GZ, Li Z, Guo L, Zhou Y, Yang HM, Sun YX. High prevalence of dyslipidemia and associated risk factors among rural Chinese adults. Lipids Health Dis. 2014;13:189.

6. Toth PP, Potter D, Ming EE. Prevalence of lipid abnormalities in the United States: the National Health and Nutrition Examination Survey 2003-2006. J Clin Lipidol. 2012;6:325-30.

7. Joffres M, Shields M, Tremblay MS, Connor Gorber S. Dyslipidemia prevalence, treatment, control, and awareness in the Canadian Health Measures Survey. Can J Public Health. 2013;104:e252-7.

8. Taheri F, Chahkandi T, Kazemi T, Bijari B, Zardast M, Namakin K. Lipid profiles and prevalence of dyslipidemia in Eastern Iranian adolescents, Birjand, 2012. Iran J Med Sci. 2015:40:341-8.

9. Verhaar MC, Stroes E, Rabelink TJ. Folates and cardiovascular disease. Arterioscler Thromb Vasc Biol. 2002;22:6-13.

10. Refsum H, Ueland PM, Nygard O, Vollset SE. Homocysteine and cardiovascular disease. Annu Rev Med. 1998;49:31-62.

11. Huo Y, Li J, Qin X, Huang Y, Wang X, Gottesman RF, et al. Efficacy of folic acid therapy in primary prevention of stroke among adults with hypertension in China: the CSPPT randomized clinical trial. JAMA. 2015:313:1325-35

12. Jiang S, Zhao R, Pan M, Venners SA, Zhong G, Hsu YH. Associations of MTHFR and MTRR polymorphisms with serum lipid levels in Chinese hypertensive patients. Clin Appl Thromb Hemost. 2014;20:400-10.

13. Lim HJ, Choi YM, Choue R. Dietary intervention with emphasis on folate intake reduces serum lipids but not plasma homocysteine levels in hyperlipidemic patients. Nutr Res. 2008;28:767-74.

14. Mohammadian Z, Eidi A, Mortazavi P, Tavangar MM, Asghari A. Effects of folic acid on dyslipidemia and serum homocysteine in a rat model of cholestasis and hepatic fibrosis. Pol J Pathol. 2015;66:49-56.

15. Frosst P, Blom HJ, Milos R, Goyette P, Sheppard CA, Matthews RG, et al. A candidate genetic risk factor for vascular disease: a common mutation in methylenetetrahydrofolate reductase. Nat Genet. 1995:10:111-3.

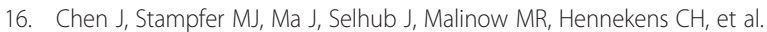
Influence of a methionine synthase (D919G) polymorphism on plasma homocysteine and folate levels and relation to risk of myocardial infarction. Atherosclerosis. 2001;154:667-72.

17. Leclerc D, Wilson A, Dumas R, Gafuik C, Song D, Watkins D, et al. Cloning and mapping of a cDNA for methionine synthase reductase, a flavoprotein defective in patients with homocystinuria. Proc Natl Acad Sci U S A. 1998;95:3059-64.

18. Martinez-Frias ML, Perez B, Desviat LR, Castro M, Leal F, Rodriguez L, et al. Maternal polymorphisms 677C-T and 1298A-C of MTHFR, and 66A-G MTRR genes: is there any relationship between polymorphisms of the folate pathway, maternal homocysteine levels, and the risk for having a child with Down syndrome? Am J Med Genet A. 2006;140:987-97.

19. Wei LK, Menon S, Griffiths LR, Gan SH. Signaling pathway genes for blood pressure, folate and cholesterol levels among hypertensives: an epistasis analysis. J Hum Hypertens. 2014;29:99-104.

20. Ou W, Liu X, Shen Y, Li J, He L, Yuan Y, et al. Association of CVD candidate gene polymorphisms with ischemic stroke and cerebral hemorrhage in Chinese individuals. PLoS One. 2014;9:e105516.

21. Yilmaz H, Agachan B, Isbir T, Akoglu E. Is there additional effect of MTHFR C677T mutation on lipid abnormalities in renal allograft recipients? Transplant Proc. 2003:35:1390-2.

22. Huang L, Song XM, Zhu WL, Li Y. Plasma homocysteine and gene polymorphisms associated with the risk of hyperlipidemia in northern Chinese subjects. Biomed Environ Sci. 2008;21:514-20.

23. Yu D, Yang L, Shen S, Fan C, Zhang W, Mo X. Association between methionine synthase reductase A66G polymorphism and the risk of congenital heart defects: evidence from eight case-control studies. Pediatr Cardiol. 2014:35:1091-8.

24. Shahzad K, Hai A, Ahmed A, Kizilbash N, Alruwaili J. A structured-based model for the decreased activity of Ala222Val and Glu429Ala Methylenetetrahydrofolate Reductase (MTHFR) mutants. Bioinformation. 2013:9:929-36.

25. Barbosa PR, Stabler SP, Machado AL, Braga RC, Hirata RD, Hirata MH, et al. Association between decreased vitamin levels and MTHFR, MTR and MTRR gene polymorphisms as determinants for elevated total homocysteine concentrations in pregnant women. Eur J Clin Nutr. 2008;62:1010-21.

26. Husemoen LL, Skaaby T, Jorgensen T, Thuesen BH, Fenger M, Grarup N, et al. MTHFR C677T genotype and cardiovascular risk in a general population without mandatory folic acid fortification. Eur J Nutr. 2014;53:1549-59.

27. Yakub M, Moti N, Parveen S, Chaudhry B, Azam I, labal MP. Polymorphisms in MTHFR, MS and CBS genes and homocysteine levels in a Pakistani population. PLoS One. 2012;7:e33222.

28. Frelut ML, Emery-Fillon N, Guilland JC, Dao JH, de Courcy GP. Alanine amino transferase concentrations are linked to folate intakes and methylenetetrahydrofolate reductase polymorphism in obese adolescent girls. J Pediatr Gastroenterol Nutr. 2006;43:234-9.

29. Jain M, Pandey P, Tiwary NK, Jain S. MTHFR C677T polymorphism is associated with hyperlipidemia in women with polycystic ovary syndrome. J Hum Reprod Sci. 2012:5:52-6.

30. Chen NY, Liu CW, Du LL, Xiao LP, Ge L, Wang YY, et al. Enrichment of MTHFR 677 T in a Chinese long-lived cohort and its association with lipid modulation. Lipids Health Dis. 2014;13:104.

31. Liang R, Zhou Y, Xie J, Lv W, Kang B, Liang Y, et al. Association of C677T gene polymorphisms of methylenetetrahydrofolate reductase and plasma homocysteine level with hyperlipidemia. Nan Fang Yi Ke Da Xue Xue Bao. 2014:34:1195-8. 
32. Mikael LG, Wang $X L$, Wu $Q$, Jiang $H$, Maclean $K N$, Rozen $R$. Hyperhomocysteinemia is associated with hypertriglyceridemia in mice with methylenetetrahydrofolate reductase deficiency. Mol Genet Metab. 2009;98:187-94.

33. Tsang BL, Devine OJ, Cordero AM, Marchetta CM, Mulinare J, Mersereau P, et al. Assessing the association between the methylenetetrahydrofolate reductase (MTHFR) 677C > T polymorphism and blood folate concentrations: a systematic review and meta-analysis of trials and observational studies. Am J Clin Nutr. 2015;101(6):1286-94.

34. da Silva RP, Kelly KB, Al Rajabi A, Jacobs RL. Novel insights on interactions between folate and lipid metabolism. Biofactors. 2014;40:277-83.

35. van der Put NM, Gabreels F, Stevens EM, Smeitink JA, Trijbels FJ, Eskes TK, et al. A second common mutation in the methylenetetrahydrofolate reductase gene: an additional risk factor for neural-tube defects? Am J Hum Genet. 1998;62:1044-51.

36. Friedman G, Goldschmidt N, Friedlander Y, Ben-Yehuda A, Selhub J, Babaey S, et al. A common mutation A1298C in human methylenetetrahydrofolate reductase gene: association with plasma total homocysteine and folate concentrations. J Nutr. 1999;129:1656-61.

37. Chang YH, Fu WM, Wu YH, Yeh CJ, Huang CN, Shiau MY. Prevalence of methylenetetrahydrofolate reductase C677T and A1298C polymorphisms in Taiwanese patients with Type 2 diabetic mellitus. Clin Biochem. 2011:44:1370-4.

38. Nakano E, Higgins JA, Powers HJ. Folate protects against oxidative modification of human LDL. Br J Nutr. 2007;86:637.

39. Olteanu H, Munson T, Banerjee R. Differences in the efficiency of reductive activation of methionine synthase and exogenous electron acceptors between the common polymorphic variants of human methionine synthase reductase. Biochemistry. 2002;41:13378-85.

40. Harmon DL, Shields DC, Woodside JV, McMaster D, Yarnell JW, Young IS, et al. Methionine synthase D919G polymorphism is a significant but modest determinant of circulating homocysteine concentrations. Genet Epidemiol. 1999;17:298-309.

41. Biselli JM, Goloni-Bertollo EM, Haddad R, Eberlin MN, Pavarino-Bertelli EC The MTR A2756G polymorphism is associated with an increase of plasma homocysteine concentration in Brazilian individuals with Down syndrome. Braz J Med Biol Res. 2008;41:34-40.

42. Jiang-Hua Q, De-Chuang J, Zhen-Duo L, Shu-de C, Zhenzhen L. Association of methylenetetrahydrofolate reductase and methionine synthase polymorphisms with breast cancer risk and interaction with folate, vitamin B6, and vitamin B 12 intakes. Tumour Biol. 2014;35:11895-901.

43. Zeng W, Liu L, Tong Y, Liu HM, Dai L, Mao M. A66G and C524T polymorphisms of the methionine synthase reductase gene are associated with congenital heart defects in the Chinese Han population. Genet Mol Res. 2011;10:2597-605.

44. Cai B, Zhang T, Zhong R, Zou L, Zhu B, Chen W, et al. Genetic variant in MTRR, but not MTR, is associated with risk of congenital heart disease: an integrated meta-analysis. PLoS One. 2014;9:e89609.

45. McNeil CJ, Hay SM, Rucklidge GJ, Reid M, Duncan G, Maloney CA, et al. Disruption of lipid metabolism in the liver of the pregnant rat fed folatedeficient and methyl donor-deficient diets. Br J Nutr. 2008;99:262-71.

46. Pravenec M, Kozich V, Krijt J, Sokolova J, Zidek V, Landa V, et al. Folate deficiency is associated with oxidative stress, increased blood pressure, and insulin resistance in spontaneously hypertensive rats. Am J Hypertens. 2013;26:135-40.

47. Akesson B, Fehling C, Jagerstad M, Stenram U. Effect of experimental folate deficiency on lipid metabolism in liver and brain. Br J Nutr. 1982;47:505-20.

48. Kim DS, Kim YK, Park HK, Cho YI, Jeong SK. Serum folate and low-density lipoprotein particle size. J Atheroscler Thromb. 2010;17:1218-25.

49. Obeid R, Herrmann W. Homocysteine and lipids: S-adenosyl methionine as a key intermediate. FEBS Lett. 2009;583:1215-25.

50. Olatunji LA, Soladoye AO. Low dietary folate impairs glucose tolerance and plasma lipid profile in oral contraceptive-treated rats. Pathophysiology. 2008;15:167-71.

51. Semmler A, Moskau S, Grigull A, Farmand S, Klockgether T, Smulders Y, et al. Plasma folate levels are associated with the lipoprotein profile: a retrospective database analysis. Nutr J. 2010;9:31.

52. Woo CW, Siow YL, Pierce GN, Choy PC, Minuk GY, Mymin D, et al. Hyperhomocysteinemia induces hepatic cholesterol biosynthesis and lipid accumulation via activation of transcription factors. Am J Physiol Endocrinol Metab. 2005;288:E1002-10.
53. Hlais S, Reslan DR, Sarieddine HK, Nasreddine L, Taan G, Azar S, et al. Effect of lysine, vitamin B(6), and carnitine supplementation on the lipid profile of male patients with hypertriglyceridemia: a 12-week, open-label, randomized, placebo-controlled trial. Clin Ther. 2012;34:1674-82.

54. Pregnolato P, Maranesi M, Marchetti M, Barzanti V, Bergami R, Tolomelli B. Interaction among dietary vitamin B6, proteins and lipids: effects on liver lipids in rats. Int J Vitam Nutr Res. 1994;64:263-9.

55. Rush EC, Katre P, Yajnik CS. Vitamin B12: one carbon metabolism, fetal growth and programming for chronic disease. Eur J Clin Nutr. 2014;68:2-7.

56. Adaikalakoteswari A, Jayashri R, Sukumar N, Venkataraman $H$, Pradeepa R, Gokulakrishnan K, et al. Vitamin B12 deficiency is associated with adverse lipid profile in Europeans and Indians with type 2 diabetes. Cardiovasc Diabetol. 2014;13:129.

57. Khaire A, Rathod R, Kale A, Joshi S. Vitamin B12 and omega-3 fatty acids together regulate lipid metabolism in Wistar rats. Prostaglandins Leukot Essent Fatty Acids. 2015;99:7-17.

58. Wasilewska A, Narkiewicz M, Rutkowski B, Lysiak-Szydlowska W. Is there any relationship between lipids and vitamin $B$ levels in persons with elevated risk of atherosclerosis? Med Sci Monit. 2003;9:CR147-51.

59. Mao G, Hong X, Xing H, Liu P, Liu H, Yu Y, et al. Efficacy of folic acid and enalapril combined therapy on reduction of blood pressure and plasma glucose: a multicenter, randomized, double-blind, parallel-controlled, clinical trial. Nutrition. 2008;24:1088-96

60. Joint Committee for Developing Chinese guidelines on Prevention and Treatment of Dyslipidemia in Adults. Chinese guidelines on prevention and treatment of dyslipidemia in adults. Clin J Cardiol. 2007;47:390-419.

61. Selhub J, Jacques PF, Dallal G, Choumenkovitch S, Rogers G. The use of blood concentrations of vitamins and their respective functional indicators to define folate and vitamin B12 status. Food Nutr Bull. 2008;29:S67-73.

62. Wu Y, Huang Y, Hu Y, Zhong J, He Z, Li W, et al. Hyperhomocysteinemia is an independent risk factor in young patients with coronary artery disease in southern China. Herz. 2013;38:779-84.

63. Mahalle N, Kulkarni MV, Garg MK, Naik SS. Vitamin B12 deficiency and hyperhomocysteinemia as correlates of cardiovascular risk factors in Indian subjects with coronary artery disease. J Cardiol. 2013;61:289-94.

\section{Submit your next manuscript to BioMed Central and take full advantage of:}

- Convenient online submission

- Thorough peer review

- No space constraints or color figure charges

- Immediate publication on acceptance

- Inclusion in PubMed, CAS, Scopus and Google Scholar

- Research which is freely available for redistribution 